\title{
Ultimate capacity of piles penetrating in weak soil layers
}

\author{
Ahmed Al-Obaidi ${ }^{1, *}$, and Pinar Mahmood ${ }^{2}$ \\ ${ }^{1}$ Civil Engineering Department, Tikrit University, Tikrit, Iraq \\ ${ }^{2}$ Ministry of Construction and Housing, Baghdad, Iraq
}

\begin{abstract}
A pile foundation is one of the most popular forms of deep foundations. They are routinely employed to transfer axial structure loads through the soft soil to stronger bearing strata. Piles generally used to increase the load carrying capacity of the foundation and reduce the settlement of the foundation. On the other hand, many cases in practice where piles pass through different layers of soil that contain weak layers located at different depths and extension, also some time cavities with a different shape, size, and depth are found. In this study, a total of 96 cases is considered and simulated in PLAXIS 2D program aiming to understand the influence of weak soil on the ultimate pile capacity. The piles embedded in the dense sand with a layer of weak soil at different extension and location. The cross section of the geometry used in this study was designed as an axisymmetric model with the 15-node element; the boundary condition recommended at least 5D in the horizontal direction, and $(\mathrm{L}+5 \mathrm{D})$ in the vertical direction where $\mathrm{D}$ and $\mathrm{L}$ are the diameter and length of pile, respectively. The soil is modeled as Mohr-Coulomb, with five input parameters and the behavior of pile material represented by the linear elastic model. The results of the above cases are compared with the results found in a pile embedded in dense soil without weak layers or cavities. The results indicated that the existence of weak soil layer within the surrounding soil around the pile decreases the ultimate capacity. Furthermore, it has been found that increase in the weak soil width (extension) leads to reduction in the ultimate capacity of the pile. This phenomenon is applicable to all depth of weak soil. The influence of weak layer extension on the ultimate capacity is less when it is presentin the upper soil layers.
\end{abstract}

\section{Introduction}

Pile foundation is one of the most popular forms of deep foundations. They are routinely employed to transfer axial structure loads through the soft soil to stronger bearing strata. Piles generally used to increase the load carrying capacity of the foundation and reduce the settlement of the foundation. These purposes are accomplished by transferring loads through a soft stratum to a stiffer stratum at a greater depth, or by distributing loads through the stratum by friction along the pile shaft, or by some combination of these two[1].

Soil can be grouped into two categories depending on the method of deposition, residual soils are formed from the weathering of rocks and transported soils are those materials that have been moved from their place of origin. The method of deposition and transportation has a significant effect on the properties of resulting soil mass [2]. So many large land areas have been formed with transported soils which deposited primarily by one of the transportation methods and may be considered as weak soil. Also, the weak soil may be a man-made soil like bad filling or accumulated debris.

Weak soil may initiate many geotechnical difficulties including inadequate bearing capacity, the potential for unacceptable settlement and slope instability [3]. So the existence of weak soil is a complex problem and difficult due to the lack of understanding of phenomena of soilpile interaction and the limited quantity and inexact quantity of soil information that can be provided for analysis [4].

There are many cases in practice where piles pass through different layers of soil that contain weak layers of soils located at different depths and locations, and some time cavities with a different shape, size, and depth.

A laboratory testing is carried out by [5] to established the performance of laterally loaded piles embedded in the soil, which contains cavities. In this study, five groups were carried out; one group included embedded pile in soil without cavities. The second and third groups are implemented on pile embedded in soil with a single cavity located in front of pile surface, in the second group, the cavity exists in the back pile surface in the third one. Group four is performed on the pile with the existence of two cavities located in front of pile surface. While the fifth group is carried out on the pile with the existence of three cavities located in front and at a variable distance from pile face. In all tests, the pile tip was free and subjected to a horizontal load. The results indicate that the number of cavities and their location

*Corresponding author: dr.obaidi.a.h@tu.edu.iq 
have a mutual effect on the behavior of laterally loaded pile, the effect of cavities found in front of the pile is insignificant at $\mathrm{X} / \mathrm{D}>8$ where $\mathrm{X}$ is the spacing between cavity and pile and $\mathrm{D}$ is the diameter of the pile.

[6], studied the interaction between cavities and adjacent axially loaded pile in clayey soil using the 3DFE program. A comparison of the behavior of load settlement curve, shear stress on the pile and lateral stress on the pile, is made for cases of the variation in the cavity positions in the vertical direction. It has been concluded that the effect of the cavity on the shear stress along pile length and on the lateral soil stress on the pile is ignored for the depth greater than $20 \%$ of the pile length from the ground level.

[7], performed a numerical study using (Plaxis 2D) to analyze the performance of the piles subjected to axial loads and to find the effect of existing weak soils and cavities on ultimate pile capacity with different locations, thickness, and soil properties. The results show that the variation between the ultimate capacity ratios with weak soil layer thickness seems to be linear for all cases for weak soil layer properties. Moreover, presence of cavity reduced the ultimate capacity ratio for the pile, the most dangerous situation when the cavity is located near the pile base. In this study, the research focused on presenting a numerical model using (PLAXIS 2D) as a finite element method to simulate and analyzed the behavior of the pile under axial loads and to find the ultimate pile capacity regards to presence of weak soil layer and cavity at different locations and different extension.

[8] Found that the agreement between numerical results of end bearing resistance of drilled shafts and available experimental and empirical relations is satisfactory. It can be concluded that the elastoplastic Mohr-Coulomb constitutive law with stress-dependent elastic parameters is suitable for numerical modeling of end bearing capacity of drilled shafts in sand and also in sandy soils, with an increase in the pile embedment depth, the end bearing capacity increases at a decreasing rate. The Numerical analyses show that at the pile tip displacement equal to $5 \%$ of pile diameter, the end bearing capacity of drilled shafts with different diameters are approximately equal. This means that the end bearing capacity is less dependent on the changes in drilled shaft diameter provided the associated tip displacement be equal to $5 \%$ pile diameter.

\section{Behavior of a single pile in layered soil}

According to [9] only punching shear failure occurs in deep foundations to attach importance to the density of the soil so long as the depth-width ratio Lid is greater than four where $\mathrm{L}=$ length of pile and $\mathrm{d}=$ diameter (or width of pile), the failure surfaces do not revert to the shaft
$Q_{u}=Q_{b}+Q_{f}=q_{0}^{\prime} N_{q} A_{b}+P \int_{0}^{L} q_{0}^{\prime^{-}} K_{S}^{-} \tan \delta \Delta L$

$Q_{u}=$ load at failure applied to the pile

$Q_{b}=$ base resistance

$Q_{f}=$ shaft resistance

$q_{0}^{\prime}=$ effective overburden pressure at the base level of the pile

$N_{q}=$ bearing capacity factors which take into account the shape factor

$A_{b}=$ bearing area of the base of the pile

$\mathrm{P}=$ Circumference

$q_{0}^{\prime^{-}}=$average effective overburden pressure over the embedded depth of the pile

$K_{S}^{-}=$average lateral earth pressure coefficient

$\delta=$ angle of wall friction

\section{Parametric study}

In the present work, two cases are simulated in PLAXIS 2D program and investigated aiming to understand the influence of weak soil on the ultimate pile capacity.

In this study, a total of 97 cases are studied that were divided into two groups; the first one included the piles embedded in dense soil only, the second group included piles embedded in the dense sand with a layer of weak soil at different extension and location (96 cases). Details of these cases are shown in Figure (1) and (2).

\section{Numerical model, step-by-step procedure in Plaxis program}

\subsection{Boundary condition}

The cross section of the geometry used in this study was designed as an axisymmetric model, and according to [10], the boundary condition recommended at least $5 \mathrm{D}$ in the lateral direction, and $(\mathrm{L}+5 \mathrm{D})$ in the vertical direction where $\mathrm{D}$ and $\mathrm{L}$ are the diameter and length of piles, respectively. These boundaries condition are necessary to minimize the boundary effect on zone around the shaft, not affecting the deformations and providing sufficient accuracy for the analysis.

\subsection{Material and properties}

In this study, the soil is modeled as Mohr-Coulomb, with five input parameters; Young's moduli, Poisson's ratio, cohesion, the angle of shearing strength, and dilatancy angle. The parameters of soil used in this study are shown in Table (1).

The material of the pile foundation used in the present work that is represented by the linear elastic model. The value of the modulus of elasticity for the pile is (30 GPa), unit weight, $\gamma_{\mathrm{c}}=25 \mathrm{kN} / \mathrm{m}^{3}$, and a Poisson's ratio, $\mathrm{v}=0.2$. 


\subsection{Mesh}

In this study, 15-node element was chosen because it is in an accurate element that can produce high-quality stress results for different problems.

\subsection{Interface}

When using 15-node soil element, the corresponding interface element is defined by five pairs of nodes, whereas for 6-node soil elements the corresponding interface elements are defined by three pairs of nodes.

\subsection{Calculations}

After the definition of the model comes the generation of initial effective stress where the pile is deactivated, and there is only soil material. The procedure considers only soil weight and calculates effective stresses in soil elements and interfaces. The initial horizontal effective stress $\sigma_{h o}^{\prime}$ is related to the initial vertical effective stress by the coefficient of earth pressure at rest $\mathrm{k}_{\mathrm{o}}\left(\sigma_{\text {ho }}^{\prime}=\right.$ $\left.k_{o} . \sigma_{v o}^{\prime}\right)$. The default $\mathrm{k}_{\mathrm{o}}$ value is based on Jaky's formula $(1-\sin \emptyset)$ for normally consolidation soils. When the K0 procedure is adopted, vertical stresses are generated in equilibrium with the self-weight of the soil.

The next step is the calculation process, which is divided into calculation phases, much like project phases. Each calculation phase is divided into some calculation steps because the non-linear behavior of the soil requires loading to apply in small proportions, called load steps.

There are many options available for calculations phase in the program; the most appropriate for the case studied is the staged construction where the user can specify a new state that is to reach at the end of calculation phase. It is possible to change the geometry and load configurations (activate pile and activate loads).

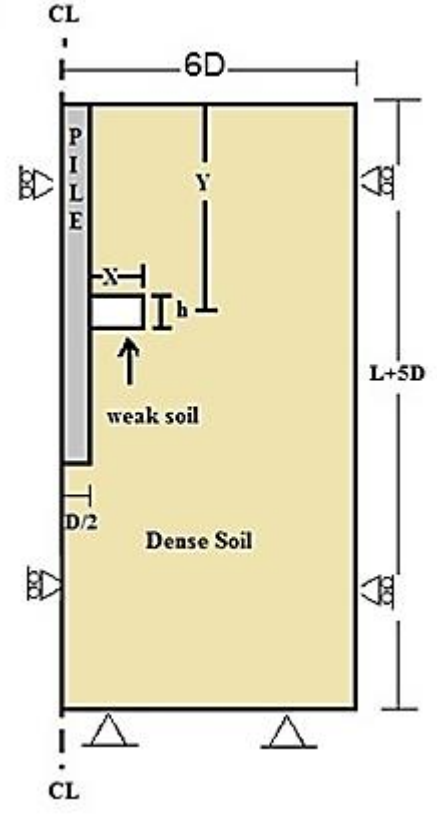

Fig. 1. Boundary condition model with existing weak soils

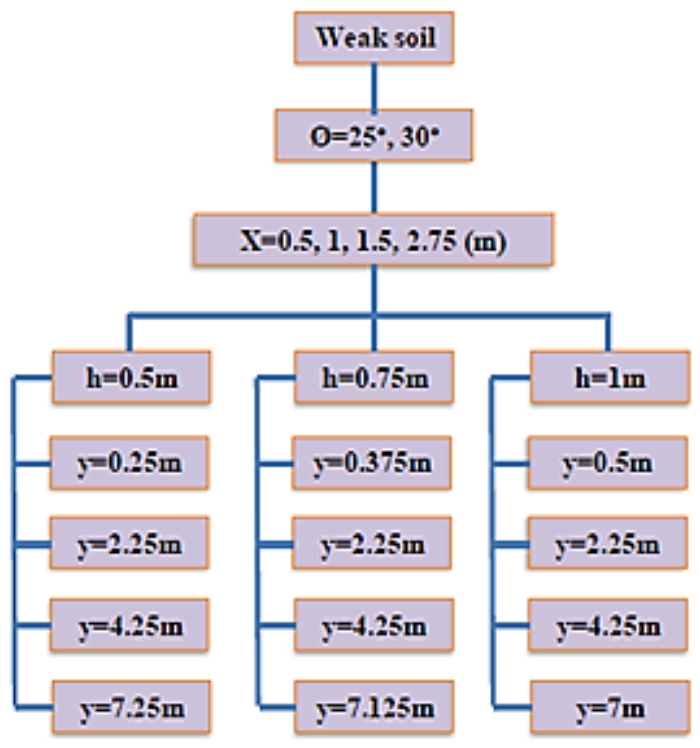

Fig. 2. Parametric study of existing weak soils

Table 1. Soil properties used in this study 


\begin{tabular}{|c|c|c|c|}
\hline \multirow{2}{*}{ Soil properties } & \multirow{2}{*}{ Dense Sand } & \multicolumn{2}{|c|}{ Weak soils } \\
\hline & & 1 & 2 \\
\hline $\begin{array}{c}\text { Modulus of elasticity, } E \\
\mathrm{kN} / \mathrm{m}^{2}\end{array}$ & 80000 & 37500 & 23500 \\
\hline $\begin{array}{c}\text { Unit weight, } \gamma \\
\mathbf{k N} / \mathrm{m}^{3}\end{array}$ & 18 & 16 & 15 \\
\hline Poisson's ratio , $\mu$ & 0.35 & 0.3 & 0.3 \\
\hline $\begin{array}{c}\text { Internal friction, } \varphi \\
\text { Degree }\end{array}$ & 40 & 30 & 25 \\
\hline $\begin{array}{c}\text { Cohesion , c } \\
\mathrm{kN} / \mathrm{m}^{2}\end{array}$ & 1 & 1 & 1 \\
\hline $\begin{array}{c}\text { Angle of dilatancy }, \Psi \\
\text { Degree }\end{array}$ & 10 & $\mathbf{0}$ & $\mathbf{0}$ \\
\hline $\begin{array}{c}\text { Interface reduction factor } \\
\mathbf{R}_{\text {inter }}\end{array}$ & 1.0 & 1.0 & 1.0 \\
\hline
\end{tabular}

\section{Results and discussion}

In the present study, a failure load defined as that which causes a settlement equal to 10 percent of the pile diameter to study the effect of weak soil on the ultimate pile capacity.

- In many soil profiles, it occasionally exists weak soil layers; these layers may be extended with limit width. In this research, the weak layer width is considered to change as $(0.5 \mathrm{~m}),(0.75 \mathrm{~m}),(1.5 \mathrm{~m})$, and fully extended, measured from pile side surface .

- Figures (3 to 5) show the effect of weak soil layer extension on the ultimate capacity ratio, (UCB) and the angle of internal friction of this layer is $25^{\circ}$. From these figures, it can be observed that the increase in the weak soil width (extension) leads to reduction of the ultimate capacity of the pile. This phenomenon is applicable to all depths of the weak soil. The influence of weak layer extension on the ultimate capacity is less when it's present in the upper soil layers. This is due to the fact that amount of the load transfer from pile to soil increased, where more load transfer at lower depths .

- The behavior of the curves in these figures indicates that ultimate pile capacity decreases with increase in weak soil layer extension (width). This is true for all weak layer thickness and depth, but the reduction in the ultimate pile capacity becomes very little and may have fixed values for certain weak soil layer width. For existing of weak soil layer at upper mid-half of the pile length, the fixed values of ultimate pile capacity may be found at the width of (1.5) $\mathrm{m}$ for weak soil layer, measured from the pile side. Existing of weak soil layer at lower depths may have constant values at more than (2.5) m width.

- Figures (6 to 8) show the effect of weak soil layer extension on the ultimate capacity ratio, the angle of internal friction of this layer is $30^{\circ}$.

- Same behaviour and effect of existing of weak soil layer as in the previous article $\left(\phi=25^{\circ}\right)$, except that, the ultimate pile capacity is greater for weak layer soil with $\left(\phi=30^{\circ}\right)$.

- Figures (9 to 11) show the effect of depth weak soil layer centre $\left(\phi=25^{\circ}\right)$ on the ultimate pile capacity, figures (12 to 14) same as above but for weak soil layer with the internal friction of $\left(\phi=30^{\circ}\right)$.

- The trend of behaviour of curves in all the figures seems to be similar, where the increasing depth of weak soil layer led to decrease the ultimate capacity ratio, regardless of the thickness of this weak soil layer. This reduction increases as the width of weak soil layer increases.

- The minimum ultimate pile capacity was found to be close to pile base, as shown in Tables (2) and (3), the reduction ranges between $(0.96-0.92)$ for weak soil layer with internal friction of $\left(\phi=25^{\circ}\right)$ and between $(0.97-0.94)$ for weak soil layer with internal friction of $\left(\phi=30^{\circ}\right)$.

\section{Conclusions}

Based on the results of the numerical study on the pile penetrate weak soil layers, the following conclusions can be drawn. Increasing of the weak soil width (extension) leads to reduction in the ultimate capacity of pile. These phenomena are applicable to all depths of the weak soil. The influence of weak layer extension on the ultimate capacity be less when it is present in the upper soil layers. For existing of weak soil layer at upper mid-half of the pile length, the fixed values of ultimate pile capacity may be found at width of (1.5) $\mathrm{m}$ for weak soil layer, measured from the pile side. Existing of weak soil layer at lower depths may have constant values at more than (2.5) m width.

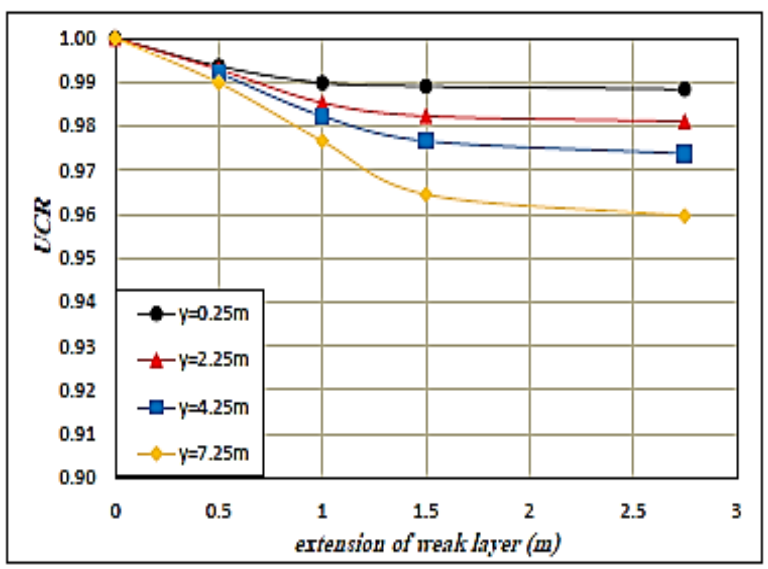

Fig. 3. Relationship between UCR and weak soil layer with thickness of $(0.5 \mathrm{~m})$ and friction angle $\left(\phi=25^{\circ}\right)$ at different depths 


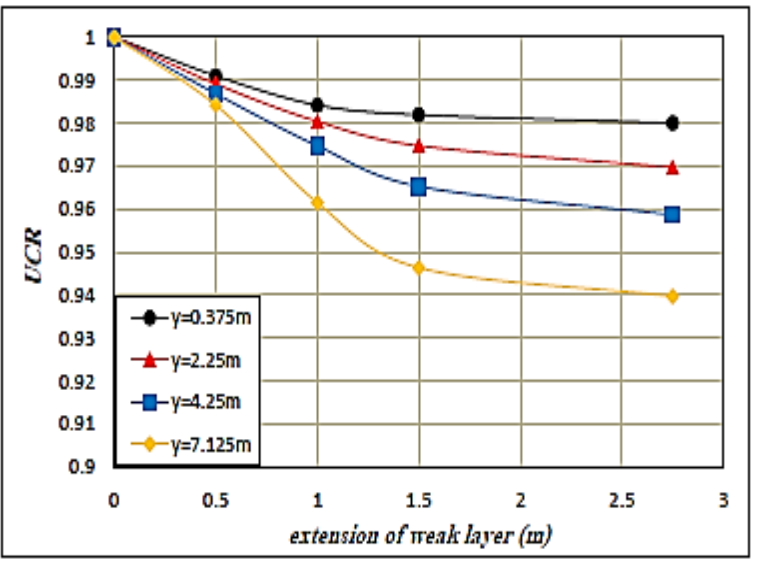

Fig.4. Relationship between UCR and weak soil layer with thickness of $(0.75 \mathrm{~m})$ and friction angle $\left(\phi=25^{\circ}\right)$ at different depths

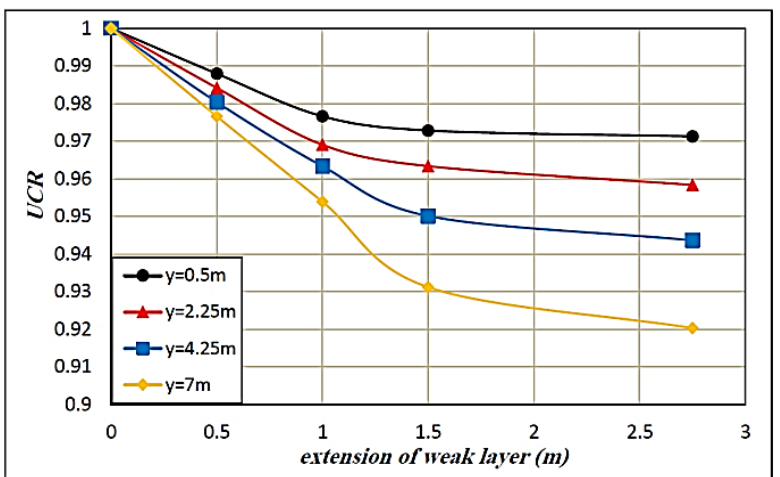

Fig.5. Relationship between UCR and weak soil layer with thickness of $(1.0 \mathrm{~m})$ and friction angle $\left(\phi=25^{\circ}\right)$ at different depths

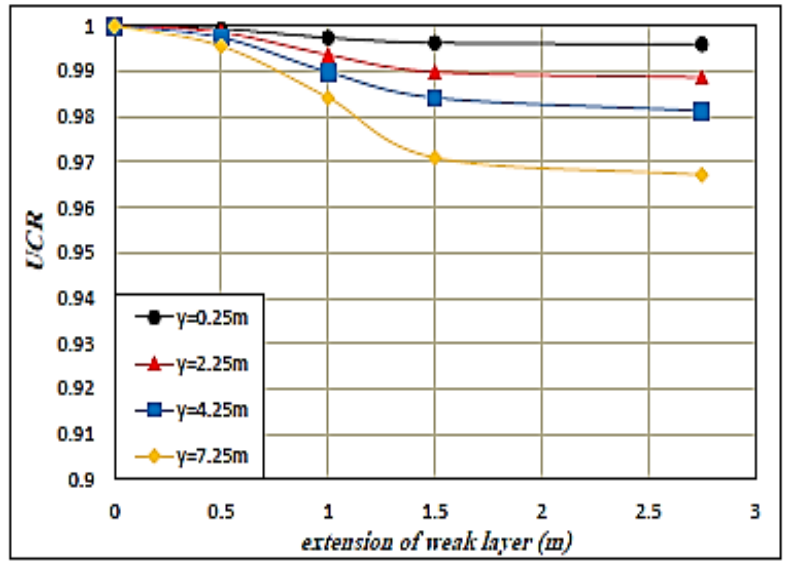

Fig.6. Relationship between UCR and weak soil layer with thickness of $(0.5 \mathrm{~m})$ and friction angle $\left(\phi=30^{\circ}\right)$ at different depths

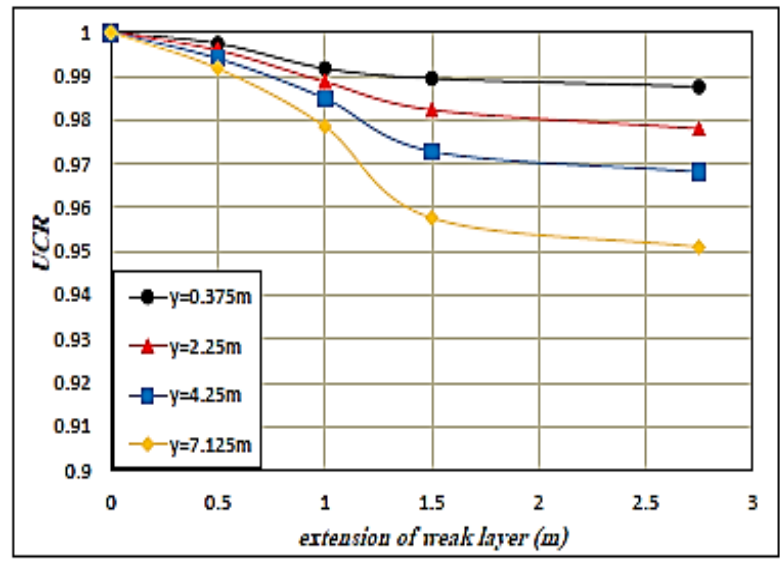

Fig.7. Relationship between UCR and weak soil layer with thickness of $(0.75 \mathrm{~m})$ and friction angle $\left(\phi=30^{\circ}\right)$ at different depths

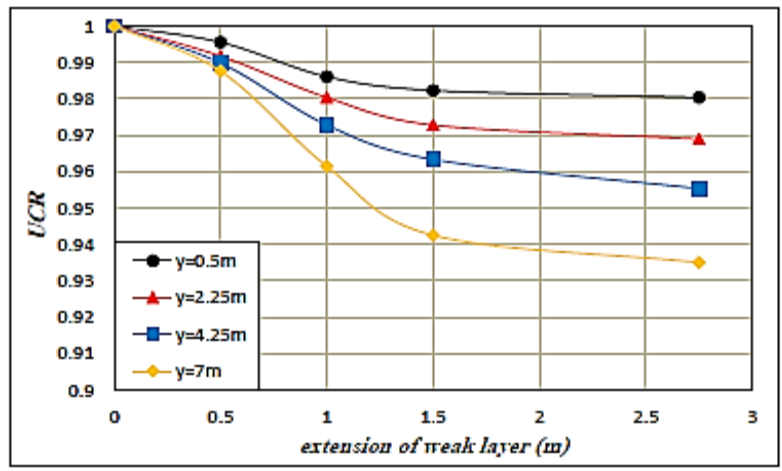

Fig.8. Relationship between UCR and weak soil layer with thickness of $(1.0 \mathrm{~m})$ and friction angle $\left(\phi=30^{\circ}\right)$ at different depths

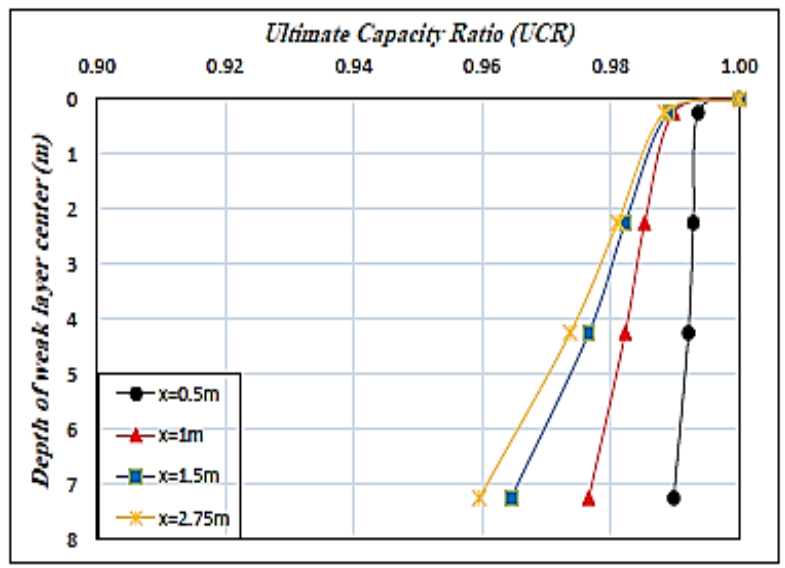

Fig.9. Relationship between UCR and Depth of weak soil layer with $(0.5 \mathrm{~m})$ thickness and friction angle of $\left(\phi=25^{\circ}\right)$ 


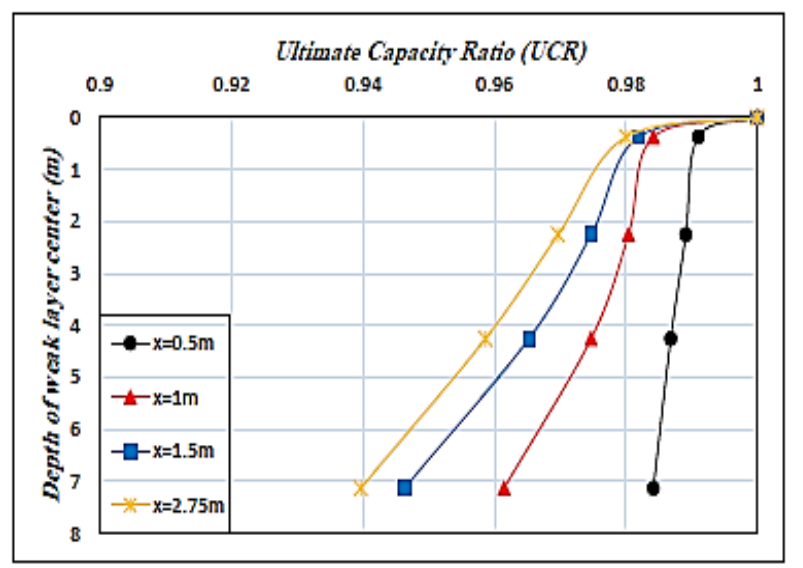

Fig.10. Relationship between UCR and Depth of weak soil layer with $(0.75 \mathrm{~m})$ thickness and friction angle of $\left(\phi=25^{\circ}\right)$

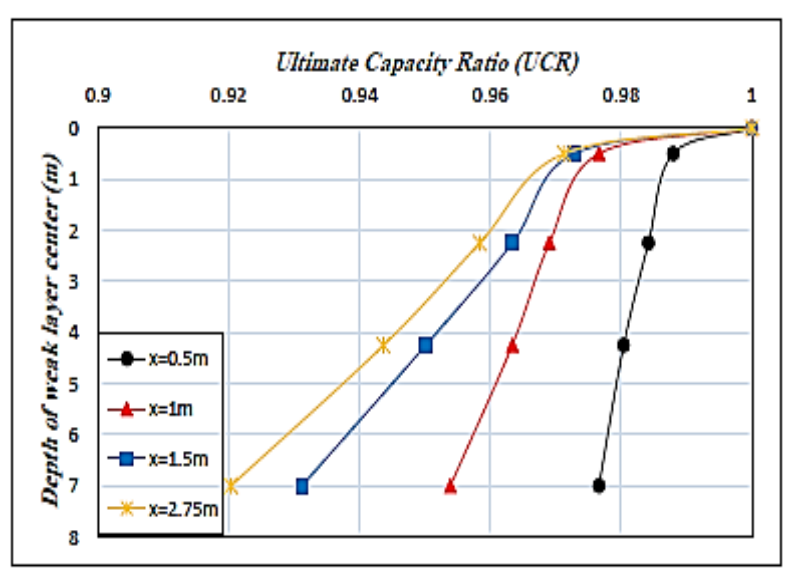

Fig.11 Relationship between UCR and Depth of weak soil layer with $(1.0 \mathrm{~m})$ thickness and friction angle of $\left(\phi=25^{\circ}\right.$

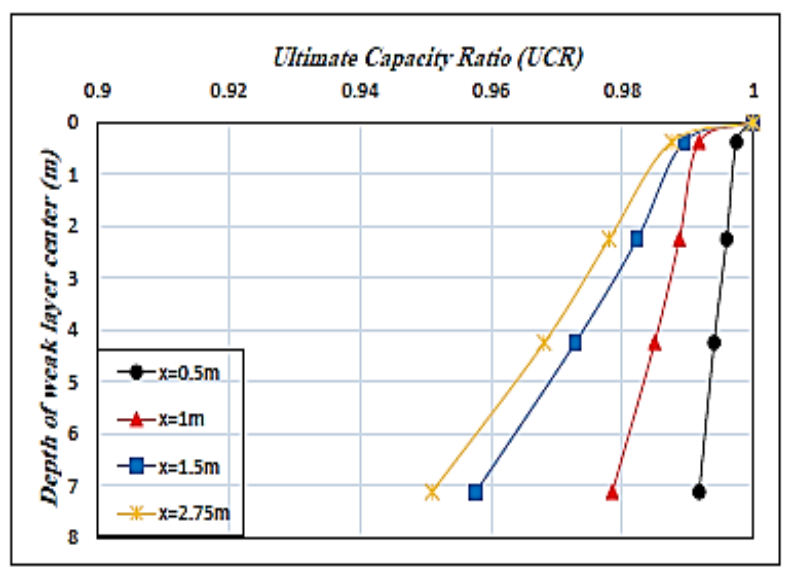

Fig.12. Relationship between UCR and Depth of weak soil layer with $(0.5 \mathrm{~m})$ thickness and friction angle of $\left(\phi=30^{\circ}\right)$

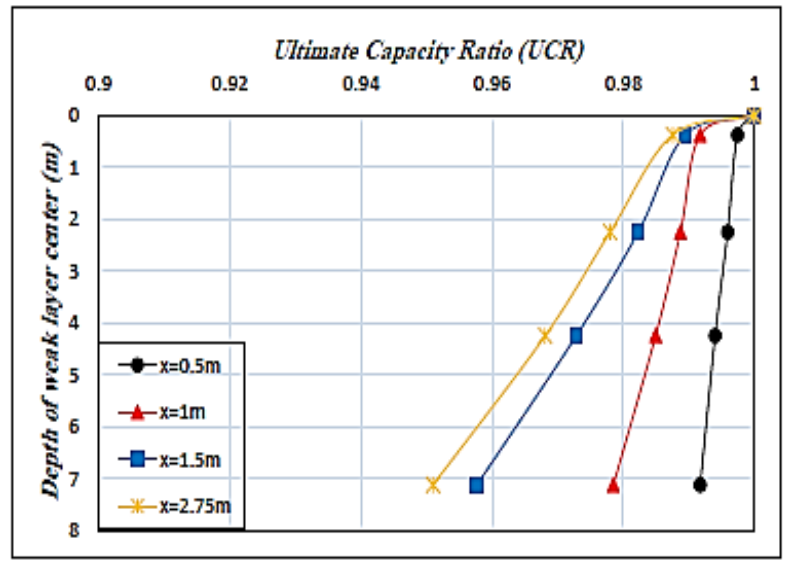

Fig.13. Relationship between UCR and Depth of weak soil layer with $(0.75 \mathrm{~m})$ thickness and friction angle of $\left(\phi=30^{\circ}\right)$

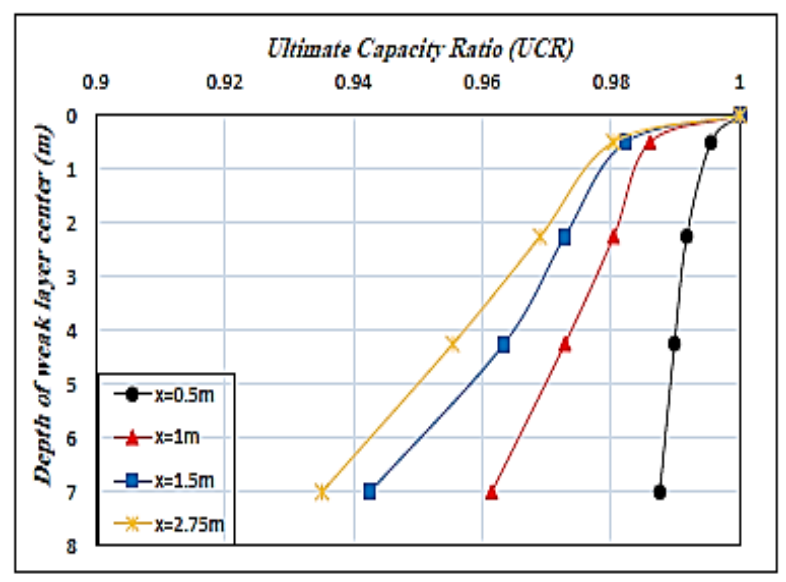

Fig.14. Relationship between UCR and Depth of weak soil layer with $(1.0 \mathrm{~m})$ thickness and friction angle of $\left(\phi=30^{\circ}\right)$

Table 2. Effect of weak soil layer $\left(\phi=25^{\circ}\right)$ depth, thickness, and extension on the ultimate capacity of pile $(\mathrm{kN})$.

\begin{tabular}{|c|c|c|c|c|c|}
\hline \multirow{2}{*}{$\begin{array}{c}\text { Depth of } \\
\text { weak } \\
\text { layer } \\
\text { (m) }\end{array}$} & \multirow{2}{*}{$\begin{array}{l}\text { Thickness } \\
\text { of weak } \\
\text { soil layer } \\
\text { (m) }\end{array}$} & \multicolumn{4}{|c|}{ Extension of weak layer (m) } \\
\hline & & 0.5 & 1.0 & 1.5 & 2.75 \\
\hline 0.25 & \multirow{4}{*}{0.5} & 2625 & 2615 & 2613 & 2611 \\
\hline 2.25 & & 2623 & 2603 & 2595 & 2591 \\
\hline 4.25 & & 2621 & 2595 & 2580 & 2572 \\
\hline 7.25 & & 2615 & 2580 & 2548 & 2535 \\
\hline 0.375 & \multirow{4}{*}{0.75} & 2618 & 2600 & 2594 & 2589 \\
\hline 2.25 & & 2613 & 2590 & 2575 & 2561 \\
\hline 4.25 & & 2607 & 2575 & 2550 & 2532 \\
\hline 7.125 & & 2600 & 2540 & 2500 & 2482 \\
\hline 0.5 & \multirow{4}{*}{1.0} & 2610 & 2580 & 2570 & 2565 \\
\hline 2.25 & & 2600 & 2560 & 2545 & 2531 \\
\hline 4.25 & & 2590 & 2545 & 2510 & 2492 \\
\hline 7.0 & & 2580 & 2520 & 2460 & 2431 \\
\hline
\end{tabular}


Table 3. Effect of weak soil layer $\left(\phi=30^{\circ}\right)$ depth, thickness, and extension on the ultimate capacity of pile $(\mathrm{kN})$.

\begin{tabular}{|c|c|c|c|c|c|}
\hline \multirow{3}{*}{$\begin{array}{c}\text { Depth of } \\
\text { weak layer } \\
\text { (m) }\end{array}$} & \multirow{3}{*}{$\begin{array}{l}\text { Thickness of } \\
\text { weak soil } \\
\text { layer (m) }\end{array}$} & \multicolumn{4}{|c|}{ Ultimate capacity of pile ( $\mathrm{kN}$ ) } \\
\hline & & \multicolumn{4}{|c|}{ Extension of weak layer (m) } \\
\hline & & 0.5 & 1.0 & 1.5 & 2.75 \\
\hline 0.25 & \multirow{4}{*}{0.5} & 2640 & 2635 & 2632 & 2631 \\
\hline 2.25 & & 2638 & 2625 & 2615 & 2611 \\
\hline 4.25 & & 2635 & 2615 & 2600 & 2592 \\
\hline 7.25 & & 2630 & 2600 & 2565 & 2555 \\
\hline 0.375 & \multirow{4}{*}{0.75} & 2635 & 2620 & 2614 & 2609 \\
\hline 2.25 & & 2630 & 2612 & 2595 & 2583 \\
\hline 4.25 & & 2626 & 2602 & 2570 & 2557 \\
\hline 7.125 & & 2620 & 2585 & 2530 & 2512 \\
\hline 0.5 & \multirow{4}{*}{1.0} & 2630 & 2605 & 2595 & 2589 \\
\hline 2.25 & & 2620 & 2590 & 2570 & 2559 \\
\hline 4.25 & & 2615 & 2570 & 2545 & 2523 \\
\hline 7.0 & & 2609 & 2540 & 2490 & 2470 \\
\hline
\end{tabular}

\section{References}

1. L. Reese, C., W. Isenhower, M. and S. Wang, Analysis and Design of Shallow and Deep Foundations, John Wiley and Sons, New York, (2006).

2. D. McCarthy, F., Essential of Soil Mechanics and Foundations, Prenticle Hall, Upper Saddle River, (2006).

3. B. Slocombe, C., Deep Compaction of Problematic Soils", Problematic Soils, Thomas Telford (London), pp: 163-181, (2001).

4. S. Akoobi, I. Effect of Stress Level of Surrounding Soil on Bored Pile Capacity in Sand ", MSc. Thesis University of Technology, The Building, and Construction Engineering Department, Geotechnical Engineering, (2012).

5. M. Al-Mosawe, J, Y. Al-Shakarchi, J. and M. AlTaie, Pile Embedded in Sandy Soil with Cavities, Journal of Engineering, No.1, Vol. 13, Baghdad university, Iraq, (2007).

6. S. Kadhim, T., Studying The Behavior of Axially Loaded Single Pile in Clayey Soil with Cavities", Eng. \& Tech, Journal, No. 8, Vol. 29, (2011).

7. A. Al-Obaidi, A, P. Mahmood, N., and A. AlKarawi, A., Assessment of Vertical Pile Capacity in Soil with Weak Layers and Cavities", $2^{\text {nd }}$ International Conference on Developments in Civil and Computer Engineering Applications, Erbil, Iraq, (2016).

8. G. Ahmadi I and S. Khabbazian M End Bearing Capacity of Drilled Shafts in Sand: A Numerical Approach" Geotechnical and Geological Engineering, Vol. 4, No. 27, pp: 195-206, (2008).

9. A. Vesic, S. A Study of Bearing Capacity of Deep Foundations, Final Report, School of Civil Eng., Georgia Inst. Tech., Atlanta, U.S.A, (1967).

10. B. Naveen, P., T. Sitharam, G. and S. Vishruth, Numerical Simulation of Vertically Loaded Piles,
Proceedings of Indian Geotechnical Conference, Kochi, No. N-118, (2011). 